\title{
On the Use of a Dimmer for a Robust Frequency Control of a Self-Excited Three-Phase Induction Wind Generator
}

\author{
Ezzeddine Touti ${ }^{\dagger}$, Remus Pusca ${ }^{*}$, Jean-Paul Manata ${ }^{*}$, Jean François Brudny ${ }^{*}$, and Abdelkader Châari ${ }^{* *}$ \\ ${ }^{\dagger}$ Department of Electric Engineering, University of Monastir, Monastir, Tunisia \\ *Laboratory of Electrical Systems and Environment (LSEE), Department of Electric Engineering, University of \\ Artois, Béthune, France \\ ${ }^{* *}$ Department of Electric Engineering, University of Tunis, Tunis, Tunisia
}

\begin{abstract}
This paper concerns a three-phase self-excited induction generator used for autonomous power generation. It presents a robust control strategy which makes it possible to maintain the frequency quasi constant during the voltage regulation without any control loop on this variable. This strategy, which also prevents the machine disengagement, uses as power converter a simple dimmer. The obtained theoretical and/or numerical results are validated on a laboratory test bench that allows the analysis of this control law effectiveness.
\end{abstract}

Key words: Dimmer, Frequency control, Self-excited induction generator, Space phasor, Voltage collapse

\section{INTRODUCTION}

Traditionally the integration of an Induction Machine (IM) in wind turbines, especially when they are in isolated sites, where the power requested is relatively limited, has become competitive which can explain their increasing in the electrical energy production [1]-[5]. An IM is simple, reliable and requires very little maintenance [6]-[10]. However, there are some difficulties associated with an IM when it operates in autonomous mode as, for example, frequency and voltage control [11], [12]. Actually many papers propose control strategies and applications of different power electronic controllers for Self Excited Induction Generator (SEIG) terminal voltage-frequency control [13], [14]. In most cases, controlled source inverters are used [15]-[18]. Other papers present the design and implementation of a SEIG electronic load controller which consists of a rectifier-chopper system feeding a resistive dump load [19]-[21]. Some works propose

Manuscript received May 6, 2013; accepted Jan. 25, 2014

Recommended for publication by Associate Editor Seung-Ho Song.

Corresponding Author: touti.these09@gmail.com

Tel: +21671445121 , University of Monastir

* Laboratory of Electrical Systems and Environment (LSEE), Department of Electric Engineering, University of Artois, France

** Department of Electric Engineering, University of Tunis, Tunisia the use of a synchronous compensators based on a STATCOM (Static Synchronous Compensator) to control the voltage and frequency [22]. Voltage source pulse width-modulated inverters are used in [23]-[26] to control the voltage and the frequency at the SEIG outputs. The use of sliding mode controllers to analyze the IM dynamic response and its behavior during load changes is presented in [27], [28]. These studies implement complex techniques. Nevertheless, these solutions increase the system cost and they are not easily possible in remote sites unreliable in critical locations.

To overcome these difficulties, and to increase the robustness of the regulation system, this paper proposes a control law developed for a parallel resistive-inductive load $(R-L)$ supplied by a SEIG. This can be considered as an introduction to the study of AC electrical motors loads. In this case, the SEIG can operate at a quasi-constant frequency without any control loop. This new control law also makes it possible to prevent the voltage collapse. The control of the frequency for a simple load (resistive load $R$ ) using a specific law has been proposed in [29]. It shows that this type of control can be a solution for remote and isolated sites. The difficulty arises when adapting the law to the complexity of 'real' loads because during regulation an important transient state can appear, as in the case of motor loads. 


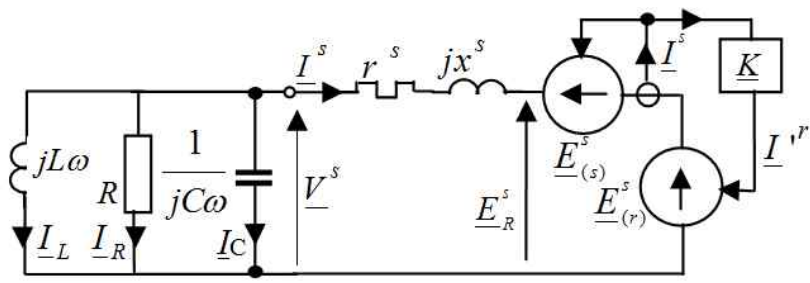

Fig. 1. Single phase equivalent circuit with a $R-L$ load.

In this paper, it is assumed that $L$ is constant and that the voltage regulation is realized when acting only on the $R$ load. The first section concerns the steady state analysis which uses for the IM a single phase equivalent circuit defined from the concept of a voltage source. The new frequency control law for the $R-L$ load is also outlined and discussed. The second section deals with the SEIG modeling based on space vector formalism. The control law effectiveness is analyzed along with its impact during transients. The numerical predictions obtained by the developed SEIG model are compared to experimental results in the last section where the test bench is also presented.

\section{STEADY StATE ANALYSIS}

\section{A. Single Phase Equivalent Circuit Model for an IM}

Using the concept of the voltage source, Fig. 1 presents a three-phase, $p$ pole pair, rotor cage IM single phase equivalent circuit considering a parallel $(R-L)$ load.

The $C$ capacity is used to provide the required reactive power for self-excitation and steady state operation [30], [31]. $\omega$ represents the stator angular frequency (frequency $f$ ). It should be pointed out that to distinguish the statoric and rotoric variables, they are labeled with the superscripts "s" and "r", respectively.

This IM, where iron losses are neglected, is characterized by the following parameters:

- $X^{s}=L^{s} \omega$, where $L^{s}$ is the cyclic magnetizing inductance, - $x^{s}=l^{s} \omega$, where $l^{s}$ is the statoric leakage inductance,

$-x^{\prime r}=l^{r} \omega$, where $l^{\prime r}$ is the rotoric leakage inductance related to the stator,

$-r^{s}$ and $r^{\prime r}$ are the statoric and rotoric related to the stator resistances.

These quantities define the $\underline{K}$ variable:

$$
\left\{\begin{array}{l}
\underline{K}=\underline{I}^{\prime r} / \underline{I}^{s} \\
\underline{K}=-j L^{s} s \omega /\left[r^{\prime r}+j\left(L^{s}+l^{\prime r}\right) s \omega\right]
\end{array}\right.
$$

where $s$ denotes the slip obtained from the rotor angular speed: $\Omega^{\prime}=(1-s) \Omega$ and the synchronous one: $\Omega=\omega / p$. As a result, the SEIG operation is characterized by the relationships:

$$
\left\{\begin{array}{l}
\underline{V}^{s}=r^{s} \underline{I}^{s}+j x^{s} \underline{I}^{s}+\underline{E}_{R}^{s} \\
\underline{E}_{R}^{s}=\underline{E}_{(s)}^{s}+\underline{E}_{(r)}^{s}
\end{array}\right.
$$

where:

$$
\left\{\begin{array}{l}
\underline{E}_{(s)}^{s}=j X^{s} \underline{I}^{s} \\
\underline{E}_{(r)}^{s}=j X^{s} \underline{I}^{\prime r} \\
\underline{E}_{R}^{s}=j X^{s} \underline{I}_{R}^{s}
\end{array}\right.
$$

$\underline{I}_{R}^{S}$ is a fictitious statoric current which leads to the same magnetic effects produced simultaneously by $\underline{I}^{s}$ and $\underline{I}^{\prime r}$ : $\underline{I}_{R}^{S}=\underline{I}^{s}+\underline{I}^{r}$

The time phasor diagram deduced from (2) to (4), considering the real and imaginary parts of the complex variables, leads to the following system:

$$
\left\{\begin{array}{l}
s^{2} \omega^{4} R L C A^{\prime}+s^{2} \omega^{2}\left[L E^{\prime \prime}-R A^{\prime}\right]+s \omega^{2} L L^{s 2} r^{\prime r}- \\
\omega^{2} R L C D^{\prime}+R D^{\prime}+\left(R+r^{s}\right) L r^{\prime r 2}=0 \\
s^{2} \omega^{4} L A^{\prime \prime}-s \omega^{4} L B+s^{2} \omega^{2} r^{s} E^{\prime}+s \omega^{2} L^{s 2} R r^{\prime r}- \\
\omega^{2} L D^{\prime \prime}+R r^{s} r^{\prime r 2}=0
\end{array}\right.
$$

Assuming that $l^{s}$ and $l^{\prime r}$, relative to $L^{s}$, are small. It is possible to express the leakage inductance as follows:

$$
\left\{\begin{array}{l}
l^{s}=\lambda^{s} L^{s} \\
l^{r r}=\lambda^{r} L^{s}
\end{array}\right.
$$

where $\lambda^{s}$ and $\lambda^{r}$ are small compared to unity. As a result, the constants $A$ ”, $B, D^{\prime \prime}, E^{\prime \prime}, A^{\prime}, D^{\prime}$ and $E^{\prime}$ are given by:

$$
\left\{\begin{array}{l}
A^{\prime \prime}=L^{s 2}\left(1+\lambda^{r}\right)\left\{\begin{array}{l}
L^{s}\left[1-\left(1+\lambda^{s}\right)\left(1+\lambda^{r}\right)\right]- \\
r^{s} R C\left(1+\lambda^{r}\right)
\end{array}\right. \\
B=L^{s 2} R C r^{\prime r} \\
D^{\prime \prime}=r^{\prime r 2}\left\{L^{s}\left(1+\lambda^{s}\right)+r^{s} R C\right\} \\
E^{\prime \prime}=L^{s 2}\left(1+\lambda^{r}\right)^{2}\left[R+r^{s}\right]
\end{array}\right\}
$$

The quantities $A^{\prime}, D^{\prime}$ and $E^{\prime}$, result from $A^{\prime \prime}, D^{\prime \prime}$ and $E^{\prime \prime}$ considering $r^{s}=0$. The $T_{e}$ IM electromagnetic torque can be expressed from the cross product [32]:

$$
T_{e}=k \vec{E}^{s}(s) \times \vec{E}^{s}(r)
$$

where: $k=3 p / \omega X^{s}$. It is possible to express the output $V^{s}$ SEIG RMS voltage from $T_{e}$ :

$$
V^{s}=\frac{R L}{L^{s}} \sqrt{\frac{T_{e} \omega}{3 p} \frac{r^{\prime r 2}+s^{2} L^{s 2}\left(1+\lambda^{r}\right)^{2} \omega^{2}}{s\left[L^{2} \omega^{2}+R^{2}\left(L C \omega^{2}-1\right)^{2}\right] r^{\prime r}}}
$$

$T_{e}$ is related to the $P_{w}$ wind power which acts on the blades: 


$$
P_{w}=\left(T_{e}+T_{f}\right) \Omega^{\prime}
$$

where $T_{f}$ represents the SEIG friction and windage torque.

\section{B. Identification of the Operating Points $(O P)$}

According to system (5), it can be seen that $\omega$ and $s$ depend only on $R, C, L$ and the IM parameters. Consequently, when these elements are imposed, the SEIG will be locked on fixed values of $\omega$ and $s$ regardless of $P_{w}$. This latter will affect only $V^{s}$. In order to illustrate the different developments, the considered IM is characterized by the rated values denoted in the appendix, and if necessary, by using the lower index "rat". For the experiments, in order to protect the IM from high damaging transients which appear during $P_{w}$ and load changes, but also to avoid magnetic saturation, the stator windings are star connected. The values of $R, C$ and $L$ are chosen such that the electrical reference Operating Point (OP), denoted with the lower index " ref ", is decreased from the rated values by a $\sqrt{3}$ ratio. Conventional no load and blocked rotor tests give the various parameters shown in the appendix.

\section{1) Approximate determination of the $O P$ : When $r^{s}, \lambda^{s}$} and $\lambda^{r}$ (denoted parasitic terms) are neglected, $\omega$ and $s$ can be identified with $\omega_{0}$ and $s_{0}$ :

$$
\left\{\begin{array}{l}
\omega_{0}=\sqrt{\left(L^{s}+L\right) / L^{s} L C} \\
s_{0}=-r^{\prime r} / R
\end{array}\right.
$$

The analysis is performed at a $f$ frequency close to $f_{\text {ref }}$, while keeping $s$ within the machine physical limits $(s>-15 \%)$. In order to really distinguish the case of an only resistive load, the load power factor is assumed in this case to be weak. For a value close to 0.45 , by using (11) it is possible to obtain for $L=L_{0}=170 \mathrm{mH}, R=R_{0}=111 \Omega$, $C=C_{0}=87.5 \mu \mathrm{F}$, the OP characterized by: $\omega_{0}=298 \mathrm{rds}{ }^{-1}$, $\left(f_{0}=47.43 \mathrm{~Hz}\right), \quad s=s_{0}=-5.4 \%$.

2) Exact determination of the $O P$ : In order to define the exact values of $\omega_{e x}$ and $s_{e x}$, the parasitic elements must be considered. Therefore, an iterative (Newton-Raphson) or graphical methods have to be used to solve system (5). In this paper, only this last solution is presented. Considering the first equation of system (5), the following equation is obtained:

$$
M_{1} \omega^{4}+N_{1} \omega^{2}+P_{1}=0
$$

Where $M_{1}, N_{1}$ and $P_{1}$ are given by:

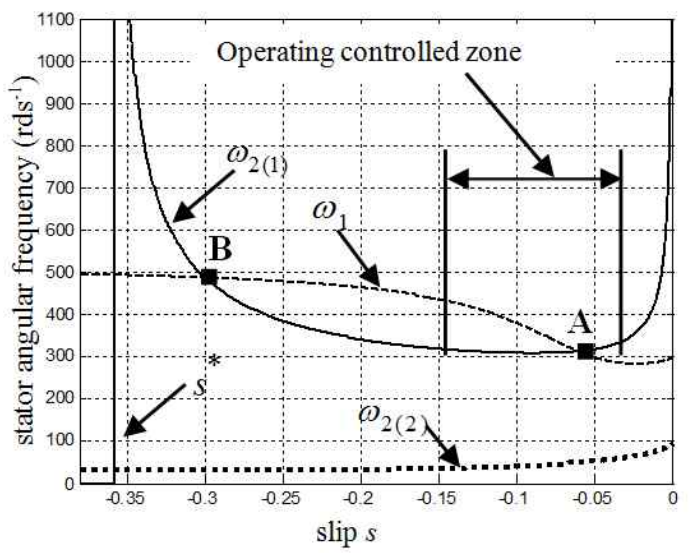

Fig. 2. Operating points for $R_{0}, C_{0}$ and $L_{0}$.

$$
\left\{\begin{array}{l}
M_{1}=L R C A^{\prime} s^{2} \\
N_{1}=\left(L E^{\prime \prime}-R A^{\prime}\right) s^{2}+L L^{s 2} r^{\prime r} s-R L C D^{\prime} \\
P_{1}=R D^{\prime}+L\left(R+r^{s}\right) r^{\prime r 2}
\end{array}\right.
$$

Taking into account that $M_{1}$ is negative and that the quantity under the radical is greater than unity, considering only the positive value of $\omega$, the root of (12) can be expressed as:

$$
\omega_{1}=\left[-N_{1}\left\{1+\sqrt{1-4 M_{1} P_{1} / N_{1}^{2}}\right\} / 2 M_{1}\right]^{1 / 2}
$$

Similar considerations lead to the $\omega_{2(1 \text { or } 2)}^{2}$ roots of the second equation of (5):

$$
\omega_{2(1 \text { or } 2)}=\left[-N_{2}\left\{1 \pm \sqrt{1-4 M_{2} P_{2} / N_{2}^{2}}\right\} / 2 M_{2}\right]^{1 / 2}
$$

where:

$$
\left\{\begin{array}{l}
M_{2}=L s\left(A^{\prime \prime} s-B\right) \\
N_{2}=r^{s} E^{\prime} s^{2}+L^{s 2} R r^{\prime r} s-L D^{\prime \prime} \\
P_{2}=R r^{s} r^{\prime r 2}
\end{array}\right.
$$

The lower index 1 between the brackets in (15) is associated with the sign + before the radical whereas the subscript 2 corresponds to the sign -. It should be pointed out that $M_{2}$ has a positive value only for: $0>s>s^{*}$ where: $s^{*}=B / A$. This means that $\omega_{2(1)}$ only exists in this range of $s$ variations while $\omega_{2(2)}$ exists in the range of $s$ between -1 and 0 , as shown in Fig. 2 plotted for $R_{0}, L_{0}$ and $C_{0}\left(s^{*}=-35.8 \%\right)$.

Since the OPs are given by the intersections of $\omega_{1}$ with $\omega_{2(1)}$ and $\omega_{2(2)}$, it appears that $\omega_{2(2)}$ does not intervene in the OP definition. As a result, only two OPs, tied to $\omega_{2(1)}$ have to be considered. The OP 'A', whose coordinates 

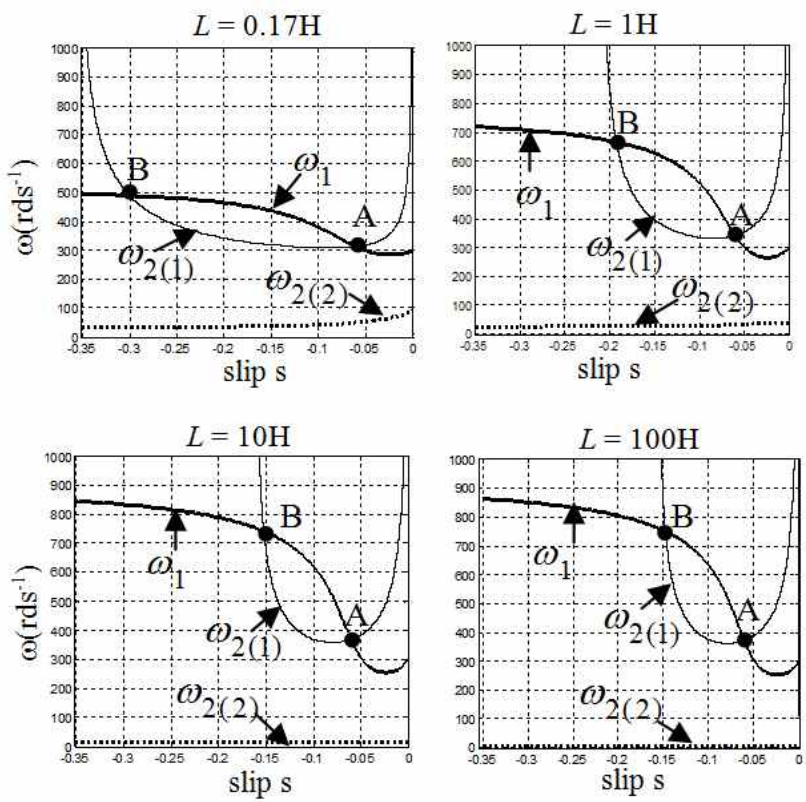

Fig. 3. Operating points for different $L$ values.

are $s_{e x}=-6.03 \%$ and $\omega_{e x}=313.2 r d s^{-1}$, is placed in the $\omega_{2(1)}$ characteristic located around $\omega_{\min }$ where the variations of $\omega$ are relatively restricted. $\omega_{\min }$ is the minimal stator angular frequency, This region, described as the stable operating zone, is limited on the left when considering the SEIG energetic performances. On the right the limitation is imposed by the frequency increase. It should be pointed out that for $P_{w}=1884 \mathrm{~W}$, (9) and (10) lead to $V^{s}=V_{r e f}^{s}$. The OP ' $\mathrm{B}$ ' is characterized by high values of $\omega$ and $s$ which may damage the SEIG energetic performance. However, the stability elementary considerations show that this $\mathrm{OP}$ is in the region qualified as an unstable $T_{e}(s)$ characteristic. As a result, this OP is practically not considered. In order to appreciate the impact of $L$ on the OPs, the cases for $L$ taking successively the values $0.17 H \quad\left(L_{0}\right), 1 H, 10 H$ and $100 H$ have been depicted in Fig. 3. The latter case ( $L=100 H$ ) can be assimilated to a resistive load. System (11) shows that $R=R_{0}$, whereas $C$ must take respectively the values of $C_{0}, 32.52 \mu \mathrm{F}$, $22.4 \mu F$ and $21.37 \mu F$. It should be noted that, regardless of the $L$ value, $\omega_{2(2)}$ never acts on the OP definition. Consequently, $\omega_{2(2)}$ will not be considered in the following developments. Moreover, it appears that $\omega_{e x}$ increases with $L$ whereas $s_{e x}$ is practically kept at a constant value. Finally, it is noted that the range for $\omega$ almost constantly increases as $L$ decreases. This can be considered as a
TABLE I

STUdied VALUES OF R AND C

\begin{tabular}{|c|ccc|}
\hline & $C_{0}=87.5 \mu F$ & $C_{1}=83.1 \mu F$ & $C_{2}=95.5 \mu F$ \\
\hline$R_{0}=111 \Omega$ & Case 00 & ----- & ----- \\
\hline$R_{1}=132 \Omega$ & Case 10 & Case 11 & ----- \\
\hline$R_{2}=86 \Omega$ & Case 20 & ----- & Case 22 \\
\hline
\end{tabular}

benefit if there are no adverse effects on the energy performance mentioned above.

\section{SEIG Operating at a Quasi Constant Frequency}

The $\omega$ relationship established for a $R$ load makes it possible to show that $f$ can be kept quasi constant for changes of $R$ when the product $R C$ is kept constant. Therefore, this condition can also be written as:

$$
R C \omega=c s t
$$

which, physically, corresponds to a constant argument of the elements connected to the SEIG outputs. A similar law can be defined considering a parallel $R-L$ load. It suffices to define an equivalent $\gamma$ capacity to the parallel $C-L$. This yields:

$$
\gamma=\left[L C \omega^{2}-1\right] / L \omega^{2}
$$

As a result, (17) can be written as:

$$
R\left[L C \omega^{2}-1\right] / L \omega=c s t
$$

Starting from OP 'A' obtained for $R_{0}, L_{0}$ and $C_{0}$, a $R$ change must be accompanied by $L$ and $C$ changes in order to obtain a new $\omega$ practical value close to the initial value. This needs to satisfy the following equality:

$$
R_{0}\left[L_{0} C_{0} \omega^{2}-1\right] / L_{0}=R\left[L C \omega^{2}-1\right] / L
$$

It is assumed that the stator voltage control is performed only adjusting $R, L$ is constant and (20) is satisfied changing only $C$. Under these conditions, (20) can be written as:

$$
R_{0}\left[L_{0} C_{0} \omega^{2}-1\right]=R\left[L_{0} C \omega^{2}-1\right]
$$

To exploit (21), one has to choose the $\omega$ value which has to be used for the $C$ determination. Since $\omega_{e x}$ is, a priori, unknown, $\omega_{\text {ref }}=\omega_{\text {rat }}$ is considered. For two values of the $R$ changes between about $\pm 20 \%$ from $R_{0}$ (these values are compatible with those considered during experiments), the corresponding $C$ values which satisfied (21) are shown along the diagonal of Table I. It should be pointed out that the use of $\omega_{e x}$ for these determinations leads to practically the same values for $C$ because $\omega_{\text {rat }}$ is very close to $\omega_{e x}$.

In this table, the selected values are chosen in order to satisfy the conditions of the operating point determination presented in section $B$. The OP position variations for only the $R$ load 

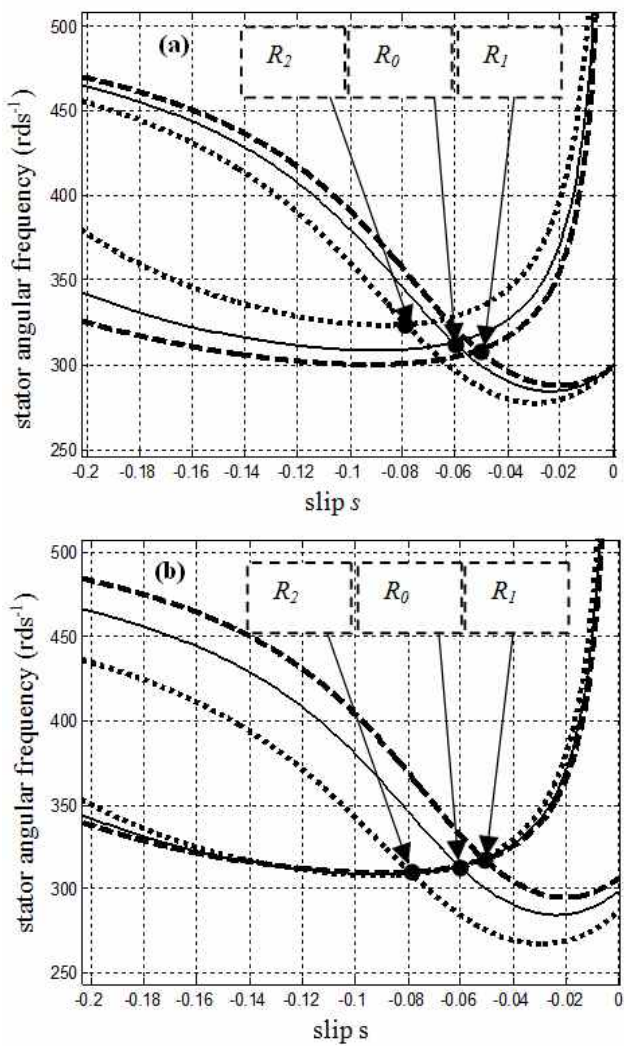

Fig. 4. Operating points positions for $R_{0}, R_{1}, R_{2}$. (a) with constant $C$. (b) with variable $C\left(C_{0}, C_{1}, C_{2}\right)$.
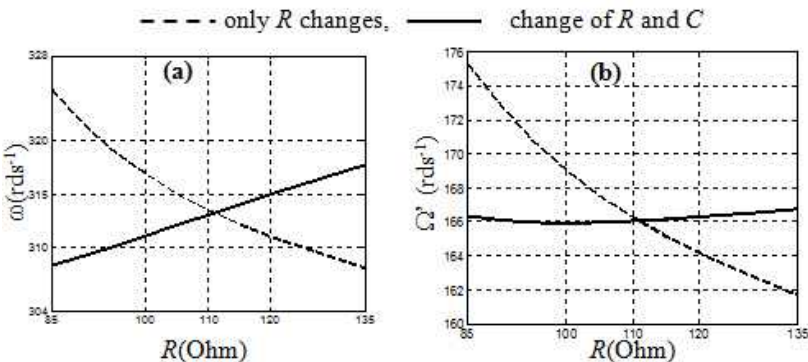

Fig. 5. - (a) $\omega$ and -(b) $\Omega^{\prime} \quad$ variations with $R$.

changes ( $L$ and $C$ are kept constant) are shown in Fig. 4.a for $R_{0}, R_{1}$ and $R_{2}$. The results presented in Fig. 4.b concern these $R$ changes with the variable $C$ and, consequently, the quantities $C_{0}, C_{1}$ and $C_{2}$, respectively. It can be observed that by applying the $f$ frequency control law it becomes possible to practically confuse the three characteristics in the controlled zone described in Fig. 2. To better appreciate the law effectiveness, Fig. 5 presents the $\omega$ (Fig. 5(a)) and $\Omega^{\prime} \quad$ (Fig. 5(b)) variations for $R \in[85 \Omega \div 135 \Omega]$.

Two cases are considered: the first case is where only $R$ changes and the second is where the pair $(R, C)$ changes. If the latter varies with respect to the suggested law, it is possible to reduce the $f$ variations in a ratio close to 2 . The

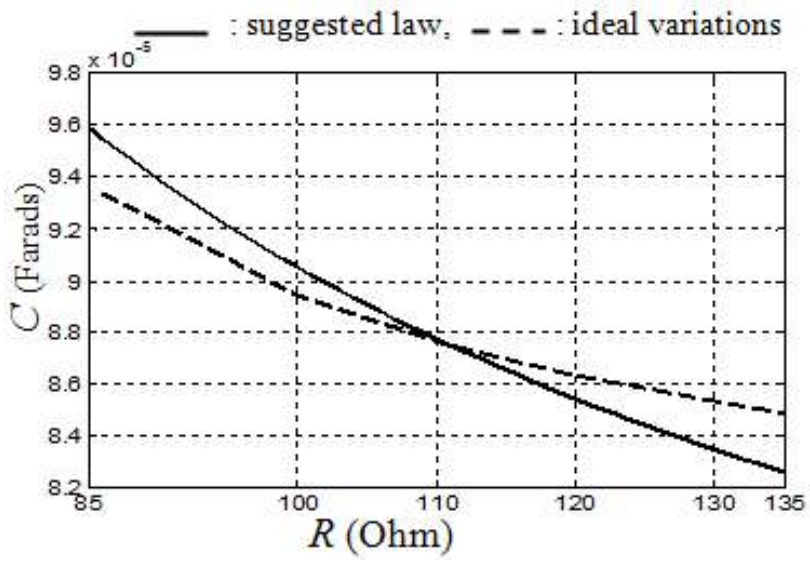

Fig. 6. Variations of $C$ with $R$.

$R$ and $C$ changes are accompanied by $S$ simultaneous variations so that $\Omega^{\prime}$ is kept nearly constant. In the considered study case, $V^{s}$ also has to be determined assuming that $P_{w}$ is constant and equal to $1884 \mathrm{~W}$. The $V^{S}$ variations are practically independent of the used strategy and are included between $191 V(R=85 \Omega)$ and $248 \mathrm{~V}(R=135 \Omega)$. This shows that regulating the SEIG output voltage by acting on the $R$ value is perfectly suited. Fig. 6 presents the $C$ variation law where $R$ satisfies (21).

The ideal variations of $C$, determined through successive iterations, which keep $\omega$ constant and equal to $\omega_{e x}$ when $R$ changes in the considered range are also presented. It is noted that the deviations of $C$, at a given $R$, are relatively weak.

Nevertheless, this leads to significant differences in the angular frequencies (Fig. 5.a) which shows the sensitivity of $\omega$ with respect to the values taken by $C$.

\section{SEIG MODELLING}

\section{A. Mathematic Formulation}

This modelling is performed considering a two pair pole IM with a three-phase equivalent rotor winding. The rotor and stator spatial references $\left(d^{r}\right.$ and $\left.d^{s}\right)$ are confused with the rotor and stator phase 1 axes. In order to take into account the SEIG self-excitation, a rotor residual magnetic field is created by means of a three phase fictitious winding, distributed on the rotor like the equivalent rotor winding. The variables corresponding to these fictitious windings are labeled with the superscript " $"$ ". The coils of $n^{a}$ turns are supplied by $i_{q}^{a}$ DC currents ( $\mathrm{q}=1,2$ or 3 ) with a null sum. The stator space phasor variables defined relative to $d^{s}$ are denoted as $\overline{\mathrm{x}}^{\mathrm{s}}$. In the same way, a rotor space phasor variable defined relative to $d^{r}$ is written as $\overline{\mathrm{X}}^{\mathrm{r}} \cdot \overline{\mathrm{X}}^{\mathrm{s}}$ is a 
stator space phasor variable defined relatively to $d^{r} \cdot \overline{\mathbf{x}}^{\mathrm{s}}$ can be deduced from $\overline{\mathrm{x}}^{\mathrm{s}}$ using the variable change: $\bar{x}^{\prime s}=\bar{x}^{s} \exp (-j \theta)$ where: $\theta=\theta_{0}+\omega^{\prime} t$ is the spatial angular gap between $d^{r}$ relatively to $d^{s}$ and $\omega^{\prime}=p \Omega^{\prime}$. Under these conditions, the IM voltage equations written in the rotor reference frame are given by:

$$
\left\{\begin{array}{l}
\bar{v}^{\prime s}=r^{s} \bar{i}^{s}+\frac{d}{d t} \bar{\psi}^{\prime s}+j \omega^{\prime} \bar{\psi}^{\prime s} \\
\bar{v}^{r}=r^{r} \bar{i}^{r}+\frac{d}{d t} \bar{\psi}^{r} \\
\bar{v}^{a}=r^{a} \bar{i}^{a}+\frac{d}{d t} \bar{\psi}^{a}
\end{array}\right.
$$

The quantities $r$ are the per phase winding resistances and the different $\bar{\psi}$ define the winding linked flux space phasors:

$$
\left\{\begin{array}{l}
\bar{\psi}^{r}=L^{r}\left(1+\lambda^{r}\right) \bar{i}^{r}+M^{r s} \bar{i}^{{ }^{s}}+M^{r a} \bar{i}^{a} \\
\bar{\psi}^{a}=L^{a}\left(1+\lambda^{a}\right) \bar{i}^{a}+M^{a s} \bar{i}^{{ }^{s}}+M^{a r^{-r}} \bar{i}^{r s}=L^{s}\left(1+\lambda^{s}\right) \bar{i}^{{ }^{s}}+M^{s r} \bar{i}^{r}+M^{s a} \bar{i}^{a}
\end{array}\right.
$$

where the different $L$ (that appear in (23)) are the main winding cyclic inductances, the $M$ quantities denote the mutual inductances between the windings, and $\lambda^{a}=l^{a} / L^{a}$ is the coefficient which characterizes the fictitious winding leakage inductances. It should be pointed out that initially, $\lambda^{r}$ has been defined from $L^{s}: \lambda^{r}=l^{r^{r}} / L^{s}$, where $l^{\prime^{r}}$ and $L^{s}$ are proportional to the squared $n^{s}$ statoric per phase effective turn number. Since $l^{r}$ and $L^{r}$ are proportional to the squared $n^{r}$ rotoric per phase effective turn number, $\lambda^{r}$ is also given by: $\lambda^{r}=l^{r} / L^{r}$. These IM equations must be added to a relationship tied to the components connected at the SEIG outputs. Fig. 1 leads to:

$$
\bar{i}^{s}=-\left(\bar{i}_{R}+\bar{i}_{C}+\bar{i}_{L}\right)
$$

Moreover, to model this SEIG during both transients and steady states, a mechanical relationship has to be considered:

$$
T_{w}=T_{e}+T_{f}+J \frac{d \Omega^{\prime}}{d t}
$$

$J$ is the overall system inertia. $T_{w}$ results from $P_{w}$ : $T_{w}=P_{w} / \Omega^{\prime} . T_{e}$ is defined by the cross product:

$$
T_{e}=3 p\left(\bar{\psi}^{s} \times \bar{i}^{s s}\right) / 2
$$

Taking into account that all of the main and mutual inductance coefficients are constants (because saturation is neglected) and that the $\bar{i}^{a}$ time derivative is null, make an easy numerical implementation of these equations possible. During the SEIG self-excited step, the $i_{q}^{a}$ currents are:

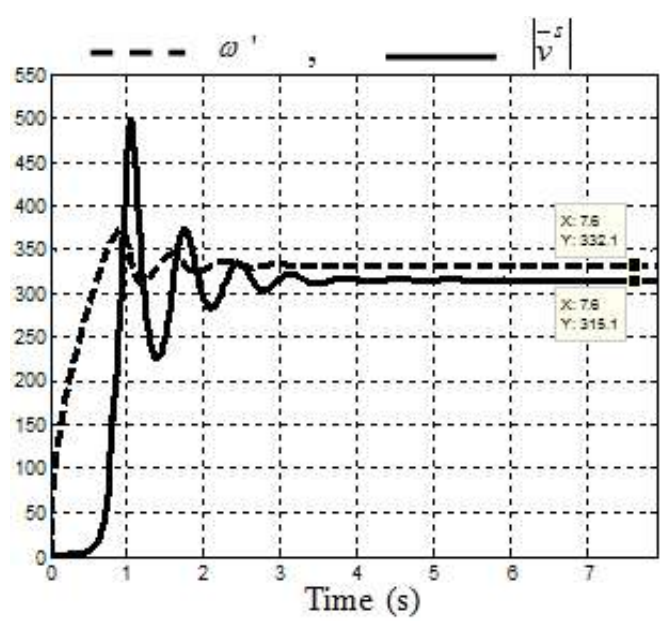

Fig. 7. Variations of $\omega^{\prime}$ and $\left|\bar{v}^{s}\right|$ during SEIG startup.

$\left|\bar{i}_{q}^{a}\right|=0.2 \mathrm{~A}$ and null after this step. The following presented results concern the variations of the $\left|\bar{v}^{s}\right|=\left|\bar{v}^{s}\right|$ modulus (solid line) expressed in (volts) and those of $\omega^{\prime}$ (dashed line) expressed in $\left(\mathrm{rd}_{\mathrm{s}} \mathrm{s}^{-1}\right)$. The variations of the last variables are shown versus time expressed in seconds (s).

\section{B. SEIG Startup}

For a constant power $P_{w}=1884 \mathrm{~W}$ applied to the SEIG shaft, the variations of the presented variables during startup are shown in Fig. 7 for $R_{0}, L_{0}$ and $C_{0}$. The steady state, that appears at $t \simeq 6 s$, is reached when $\bar{i}^{s}, \bar{i}^{r}$ and $\bar{v}^{\prime s}$ possess constant moduli and turn at the same $s \omega$ speed. It appears that in the steady state, $s \omega=18.9 r d s^{-1}$ for $\omega=314.2 r d s^{-1}, s=5.4 \%$ and $V^{s}=223 \mathrm{~V}$. An important voltage peak value appears during the transient which can damage the SEIG. Consequently, in practice, a device must be added in order to protect the IM and the components connected at its outputs. This justifies the choices made in this study: $V_{\text {ref }}^{s}<V_{\text {rat }}^{s}$.

\section{Transient State for Constant Shaft Power $P_{w}$}

The curves shown in Fig. 8 present an example of the $\left|\bar{v}^{s}\right|$ and $\omega^{\prime}$ variations with time for a constant $P_{w}$ equal to $1884 \mathrm{~W}$ and for a $R$ change at $t=8 \mathrm{~s}$. Fig. 8(a) is relative to the case $00 \rightarrow$ case 20 change but Fig. $8(\mathrm{~b})$ concerns the case $00 \rightarrow$ case 22 change. It first appears that the maximum variations of $\left|\bar{v}^{s}\right|$ and $\omega^{\prime}$ are reduced when the suggested law is used. On the other hand, this law leads to an important increase in the speed when $C$ is kept constant. In fact, the 

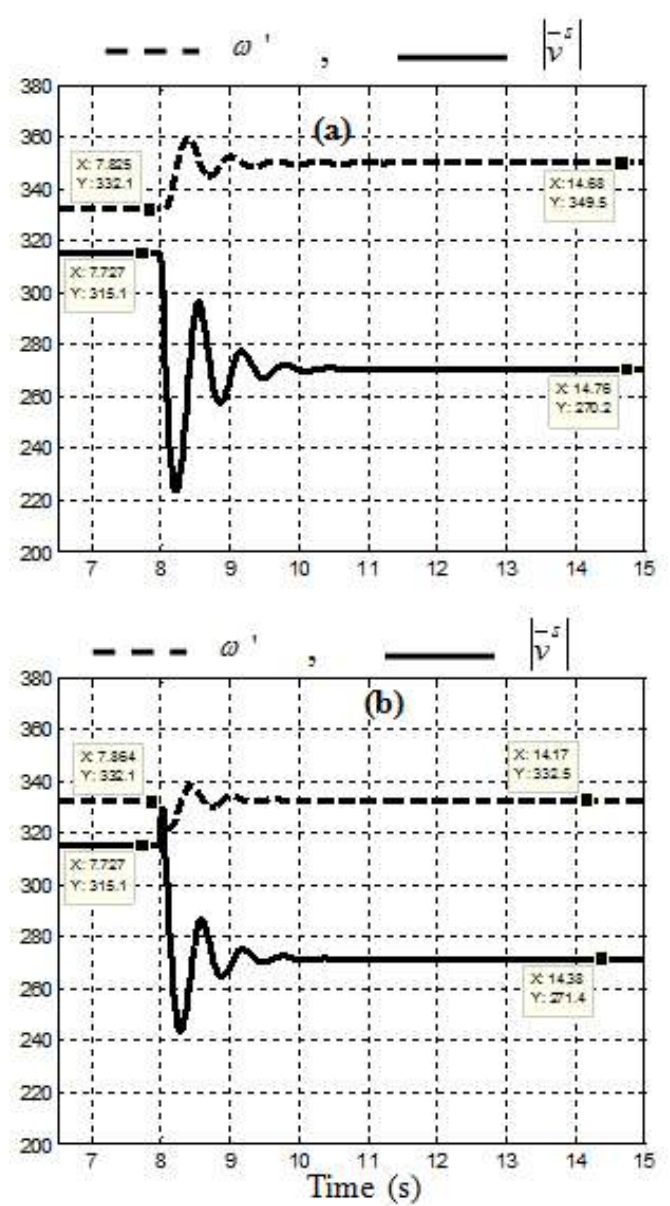

Fig. 8. Variations of $\omega^{\prime}$ and $\left|v^{s}\right|$ for constant $P_{w}$ : -(a) only $R$ changes; -(b) $R$ and $C$ change.

latter increases by $5.24 \%$ in the steady state speed in Fig. 8 (a) and by $0.12 \%$ in Fig. $8(\mathrm{~b})$.

The obtained simulation results show that considering (21) the frequency can be kept quasi constant with an improved transient state.

\section{Transient State for Variable Shaft Power $P_{w}$}

In the steady state, for $R_{0}, L_{0}, C_{0}$ and $P_{w}=1884 \mathrm{~W}$, it is assumed that at $t=8 \mathrm{~s}, P_{w}$ varies while taking the $2204 \mathrm{~W}$ value. Regulation occurs at $t=8.05 \mathrm{~s}$. Fig. 9(a) shows the variations of $\omega^{\prime}$ and $\left|\bar{v}^{s}\right|$ when only $R$ changes (case 00 to case 20, Table I) in order to keep $\left|\bar{v}^{s}\right|$ constant. First of all, the relatively high transients on the speed and voltage should be noted. If the new steady state is characterized by a voltage which is nearly identical to that existing before the state change, it is not the case for the speed which increase considerably decreasing $s$ (from $-6.03 \%$ to $-7.75 \%$ ). Fig. 9(b) shows these variable variations when $R$ and $C$ vary simultaneously: case $00 \rightarrow$
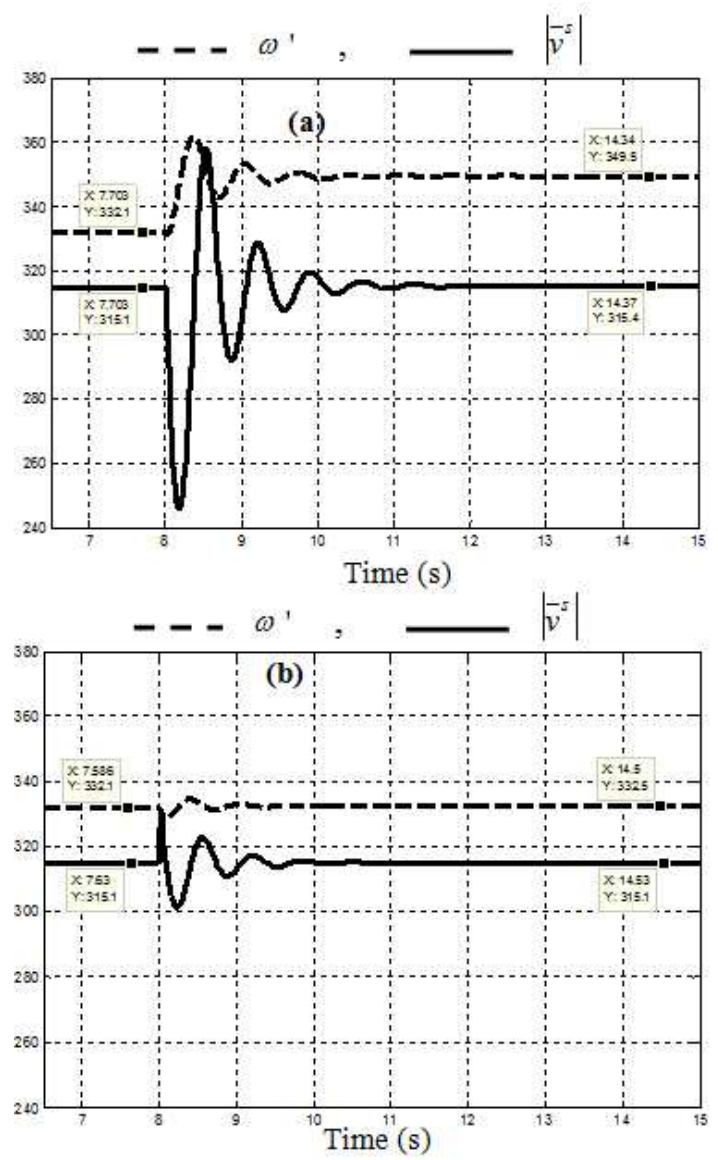

Fig. 9. Variations of $\omega^{\prime}$ and $\left|v^{s}\right|$ for $P_{w}$ change from $1884 \mathrm{~W}$ to $2204 \mathrm{~W}$ : -(a) only $R$ changes; -(b) $R$ and $C$ change.

case 22. The voltage regulation is also effective. However, it strongly attenuated the transients in amplitude and duration. The final steady state is characterized by a speed close to that existing before the $P_{w}$ change.

\section{E. Voltage Collapse}

Starting from the steady state corresponding to case 00 and $P_{w}=1884 \mathrm{~W}$, it is assumed that at $t=8 \mathrm{~s}, R$ varies taking the $61 \Omega$ value. Fig. 10.a shows the variable variations with time which correspond to a voltage collapse characterized by a voltage drop and an IM acceleration. The same switching to $R=61 \Omega$ accompanied by a $C$ change according to the suggested law, is presented in Fig. 10.b. It appears that following a relatively severe transient on the voltages, the SEIG manages to return to an operational steady state with a decrease in the voltage and an increase in the rotor angular speed (from $\omega^{\prime}=332.1 r d s^{-1}$ to $\omega^{\prime}=345.1 r d s^{-1}$ ). However, the $\omega^{\prime}$ variation has a slight influence on the $f$ modification (frequency changes from $f=49.8 \mathrm{~Hz}$ to $f=49.3 \mathrm{~Hz}$ ) because the slip $s$ is changed to reach 

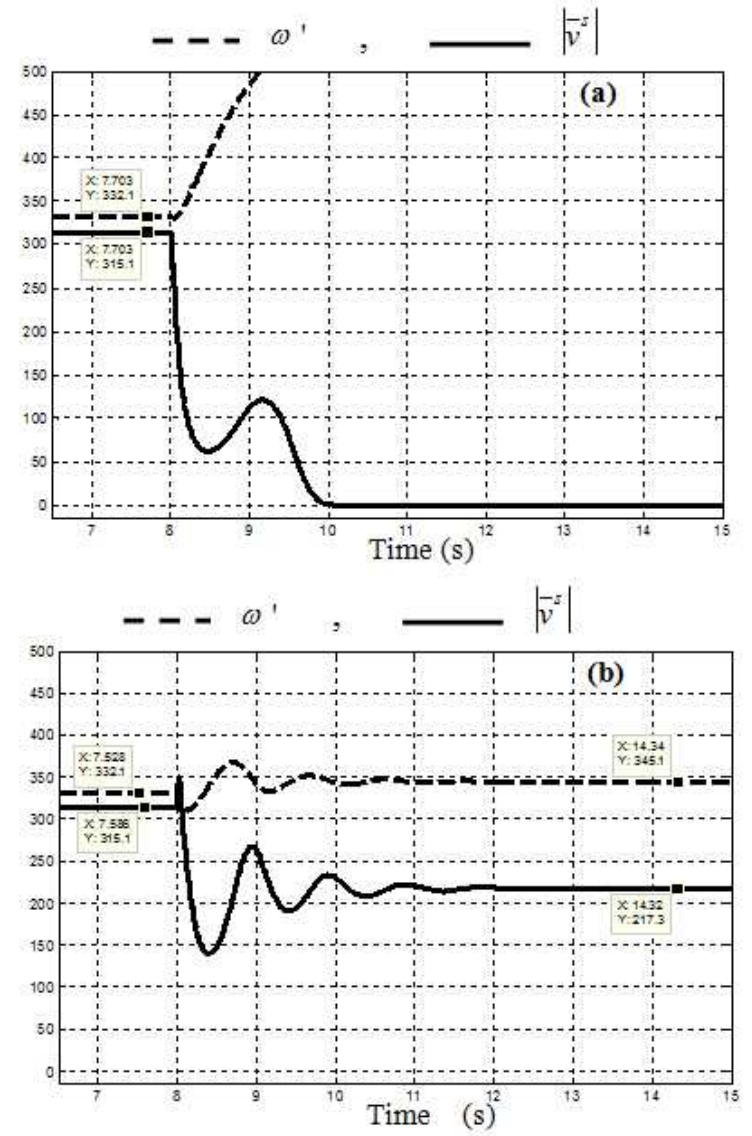

Fig. 10. Variations of $\omega^{\prime}$ and $\left|\bar{v}^{s}\right|$ at $P_{w}=1884 \mathrm{~W}$. (a) Only $R$ changes. (b) $R$ and $C$ change.

$$
s=-11.25 \% \quad\left(\omega=\omega^{\prime} /(1-s)=310.1 r d s^{-1}\right) .
$$

\section{EXPERIMENTAL STUDY}

\section{A. Test Bench Presentation}

In order to validate the analytical and numerical results, a test bench (Fig. 11) is used. It consists of a DC motor, operating at a constant magnetic flux $\phi$, mechanically associated with an IM which operates as a SEIG. There are two problems for implementing such a system: the first consists of providing a $P_{w}$ control on the IM shaft, the second is to provide a variable $C$ capacitor which changes with $R$ according to the relationship in (21).

1) Regulation of $P_{w}:$ In order to control $P_{w}$, the DC motor is connected at the chopper outputs supplied with the constant $U_{0}$ DC voltage. This chopper is controlled by a data acquisition numerical system (dSPACE \& Matlab) which samples the $i_{D C}$ current of the DC motor. The dSPACE system uses as an input $i_{D C}$ in order to provide a $\beta$ analogical signal which controls the chopper operation. This machine is compensated which allows it to neglect the inductive effects.

The $T_{D C}$ DC machine electromagnetic torque is given by:

$$
T_{D C}=K_{D C} i_{D C}
$$

where $K_{D C}=K^{\prime} \phi$, with $K^{\prime}$ being a constant tied to the DC machine design. In the operating range considered for this analysis, the $T_{f D C}$ SEIG friction and windage torque can be assumed to be constant.

The torque which acts on the IM shaft is given by:

$$
T_{w}=T_{D C}-T_{f D C}
$$

The $P_{w}$ power results from the relationship:

$$
P_{w}=\beta U_{0} i_{D C}-R_{D C} i_{D C}^{2}-T_{f D C} \Omega^{\prime}
$$

where $R_{D C}$ is the DC machine armature resistance. Given $U_{0}, T_{f D C}, R_{D C}$ and $i_{D C}$, the dSPACE system can compute $\beta$ from (29) in order to control $P_{w}$.

In (29), the speed $\Omega^{\prime}$ is estimated using the relationship:

$$
\Omega^{\prime}=\left(\beta U_{0}-R_{D C} i_{D C}\right) / K_{D C}
$$

It should be noted that the different parameters of this practical bench will be given in the appendix.

2) C Capacity variation: For a given $R-L$ load, the first step consists of finding by numerical simulation adequate pairs $(R, C)$ using the analytical method described in section II. This leads to some OP within the zone which can be described as stable (Fig. 2).

The voltage regulation is performed with $R$ variations using controlled mechanical switches (Fig. 11). For this application, several $R$ discrete values are used. The $C$ changes are obtained using a fixed capacitor $\left(C_{M}>C\right)$ parallel connected with a fixed $L_{R}$ inductance series connected with a dimmer, as shown in Fig. 12. This leads, for a given frequency close to $f_{\text {rat }}$, to different $\alpha$ dimmer firing angles whose values have to be computed and incorporated into the «control logic» block (Fig. 11). The developments realized for the $\alpha$ calculus are those presented in [33].

\section{B. Validation of the Numerical Model in the Steady State}

The experiment has been done at a constant $P_{w}$ equal to $1884 \mathrm{~W}$ with a starting point relative to $R_{0}, L_{0}$ and $C_{0}$. The changing limit values given in section II are those corresponding to case 22 and case 11 (Table I). The values, presented in Table II, show the $f$ and $\Omega^{\prime}$ variations with $R$ changes while taking into account the theoretical and experimental values.

One can note that $f$ presents weak variations between the theoretical and experimental values which seem to be 


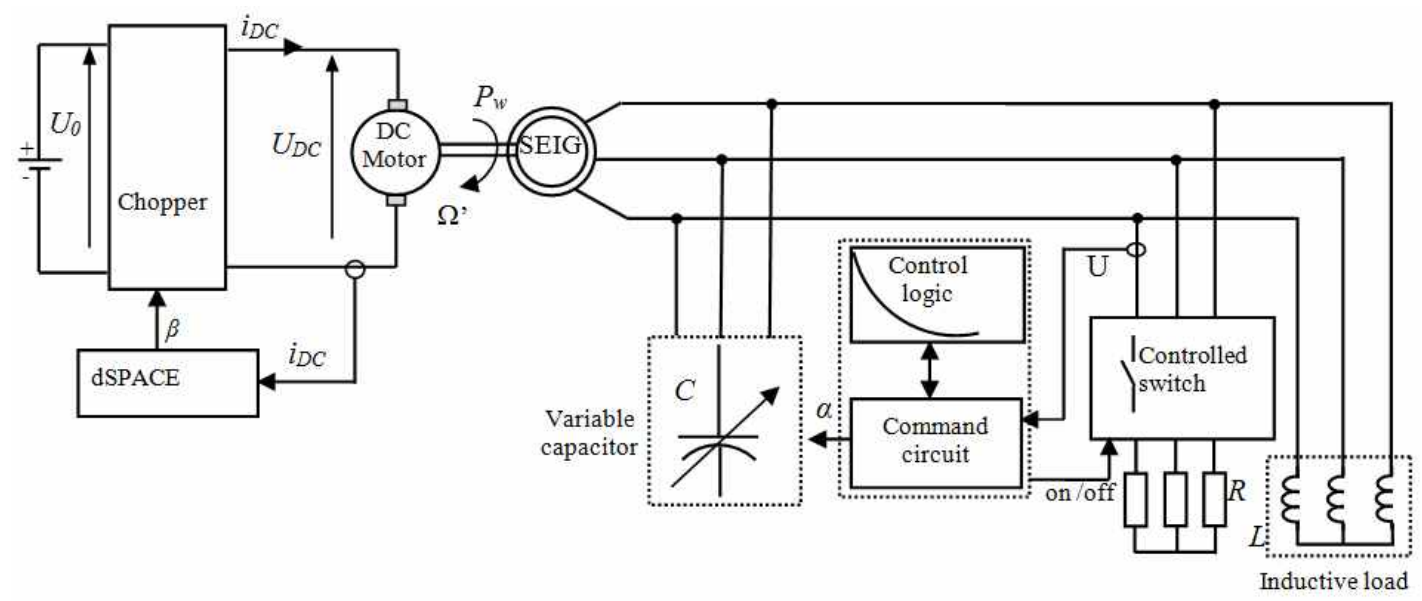

Fig. 11. Test bench schematic diagram.

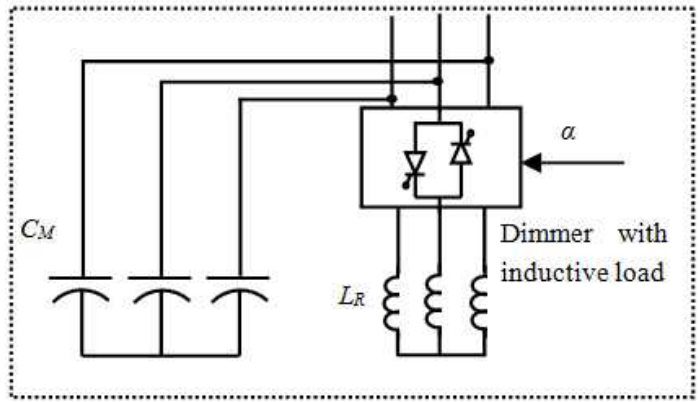

Fig. 12. Variable $C$ capacitor realization.

compensated by following the $S$ variations as it can be shown in the variation of the $\Omega^{\prime}$ values. The theoretical and experimental $\Omega^{\prime}$ variations are nearly very close. One can remark here a robust frequency control obtained by the capacity variation using the suggested law given by (21).

\section{Validation of the Numerical Model during Transients at a Constant $P_{w}$}

The curves presented in Fig. 13 show the $\left|\bar{v}^{s}\right|$ variations when $R$ changes for a constant $P_{w}$ equal to $1884 \mathrm{~W}$. This example corresponds to that presented in section III.C. Fig. 13(a) is relative to case 20 and Fig. 13(b) concerns a change to case 22. In Fig. 13(a), the SEIG reaches the steady state after a relatively large transient. This transient state is accompanied by an important overvoltage which may trigger the protection systems leading to a disconnection of the SEIG. Fig. 13(b) shows reduced $\left|\bar{v}^{s}\right|$ variations (decreased to half) during the transient state.

This is an improvement obtained by the use of the proposed law. It can be seen that these experimental results are close to those obtained by the simulation (Fig. 8) with a transient state duration that is slightly greater in the experimental case.
TABLE II

StUdied Tests

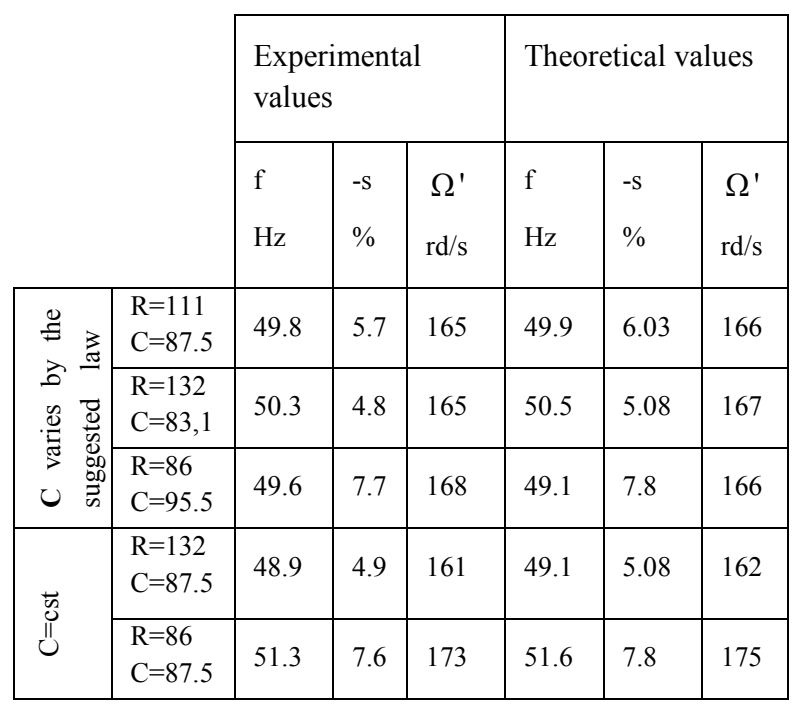

For validation of the $P_{w}$ control law, the case corresponded to a load variation (case 00 to case 22) considering the $P_{w}$ constant is shown in Fig. 14. The curves are plotted in per unit taking into account the variable values obtained before the transient as references: $P_{w_{\text {ref }}}^{*}=1884 \mathrm{~W}$, $\left|\bar{v}^{s}\right|_{r e f}^{*}=315 \mathrm{~V}, \quad i_{D C_{\text {ref }}}^{*}=10.7 \mathrm{~A} \quad$ and $\quad U_{D C_{r e f}}^{*}=197 \mathrm{~V}$.

However, these curves are delayed with adapted coefficients in order to keep figure clarity. In Fig. 14, the per unit values are multiplied by: 1 for $\left|\bar{v}^{s}\right|, 1.55$ for $U_{D C}, 1.65$ for $i_{D C}$ and 2 for $P_{w}$.

It can be seen that during the load changes, the average $i_{D C}$ and $U_{D C}$ values are modified but $P_{w}$ is maintained at a quasi-constant value by the dSPACE control. It should be 

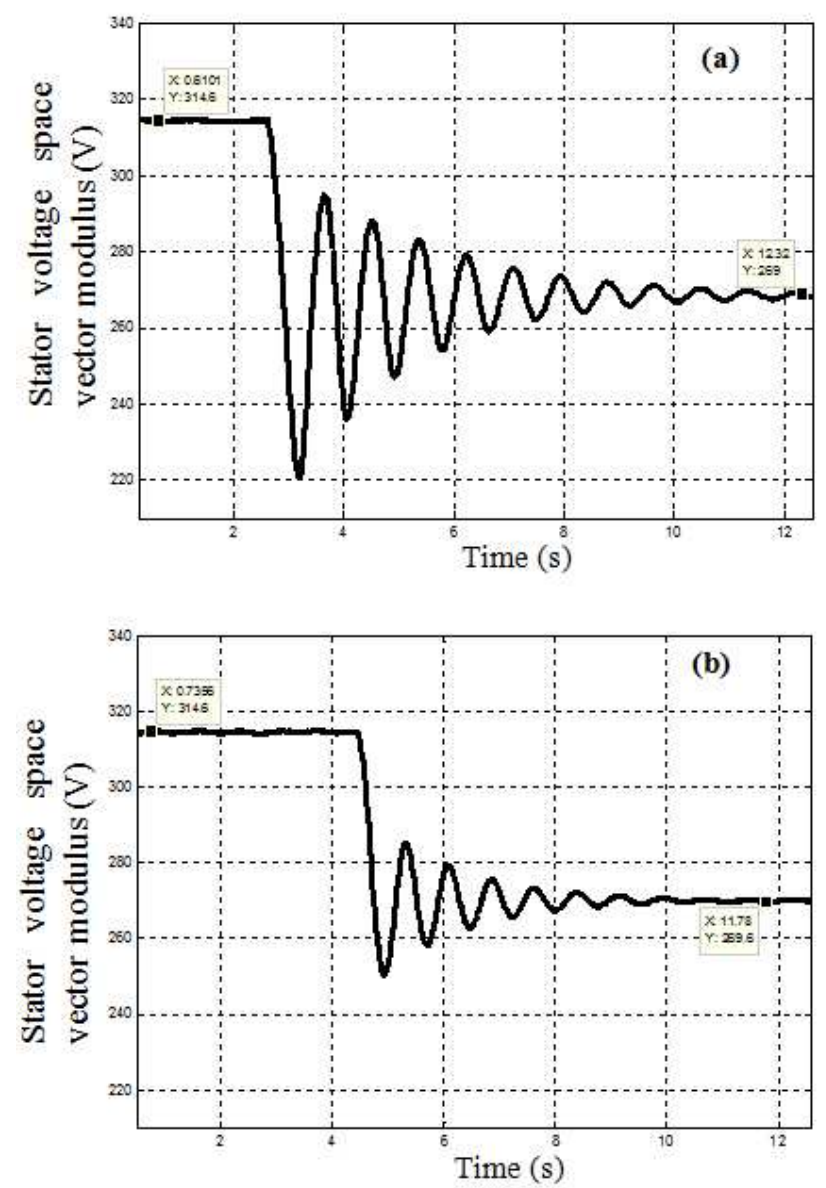

Fig. 13. Variations of $\left|\bar{v}^{s}\right|$ at constant $P_{w}$. (a) Only $R$ changes. (b) change of $R$ and $C$.

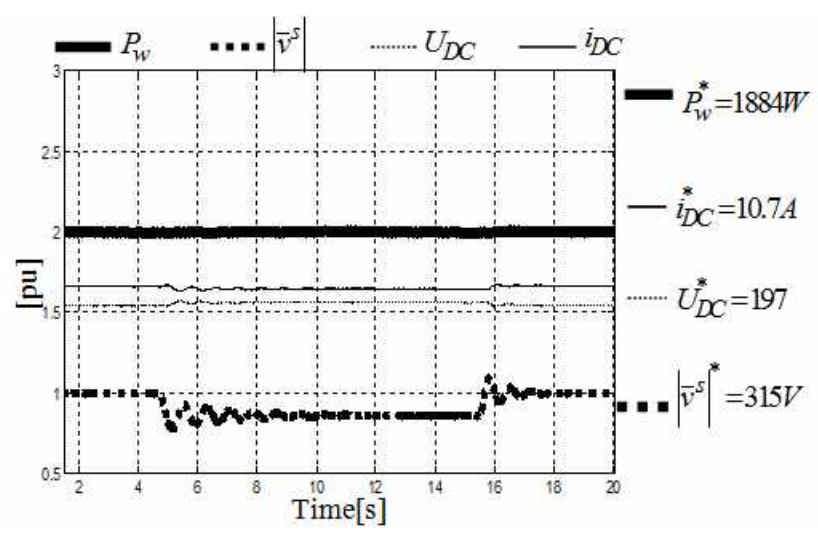

Fig. 14. $\left|\bar{v}^{s}\right|, U_{D C}, i_{D C}$ and $P_{w}$ variations for constant $P_{w}^{*}$.

noted that there is a decrease of the $\left|\bar{v}^{s}\right|$ values with weak variations during the transient regime. In this case only the frequency is kept constant. These measured values correspond to the case simulated in Fig. 8(b).

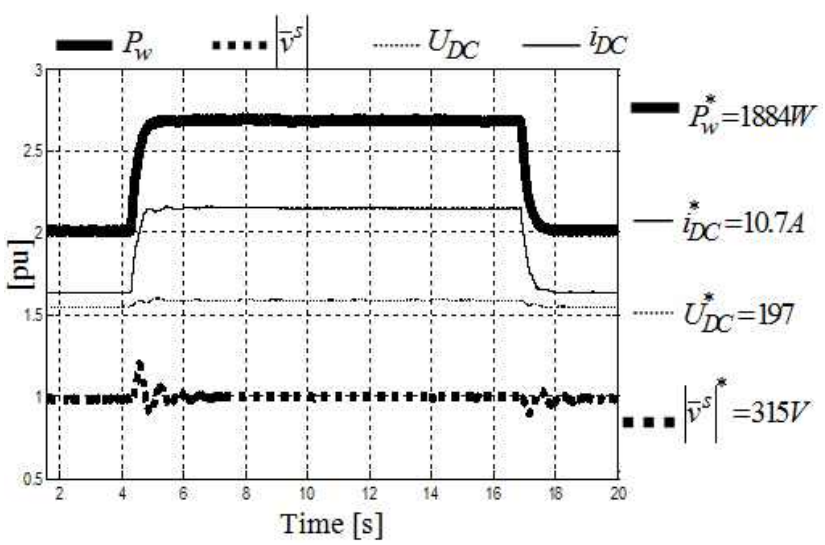

Fig. 15. $\left|\bar{v}^{s}\right|, U_{D C}, i_{D C}$ and $P_{w}$ variations for variable $P_{w}^{*}$.

\section{Validation of the numerical model during transients at variable $P_{w}$}

The variable variations when $P_{w}$ varies and the load changes from case 00 to case 22 are shown in Fig. 15. The curves are plotted in per unit values and are multiplied by the same coefficient used in Fig. 14. This case validates the $\left|\bar{v}^{s}\right|$ regulation law as simulated in Fig. 9. b. For this case the transient state is improved, $\left|\bar{v}^{s}\right|$ is stabilized and $f$ is kept at a constant value.

\section{CONCLUSIONS}

The presented study was developed to ensure a robust frequency control for a Self Excited Induction Generator which supplies a $R-L$ load connected in parallel with capacitor banks. The steady state analysis developed in this paper uses the single-phase equivalent circuit definition taking into account the concept of an induced voltage source and IM space vector formalism. This analysis shows that the presence of the $L$ component in the load naturally enhances the system stability and reveals the operating zones where the SEIG behavior can be controlled. It also revealed operation at a quasi constant frequency without the need for a control loop of the latter. This has been possible by means of changing the $C$ capacitor with $R$ changes, in the case of load variations, according to the defined law presented in this paper. This control law enhances also the transient state. For strong $R$ variations, this control strategy prevents the voltage collapse through changes of the reactive power supplied by the capacitor bank. This reactive power must vary continuously with load variations according to the law already studied. In the test bench, the reactive power variation is ensured by a three-phase dimmer. The experimental tests validated the developed analytical control law and the numerical results, showing an improvement of the transient state, when the presented law is used. Through this analysis, it can be 
concluded that the values obtained by simulation and those obtained experimentally are in agreement. By comparison with the work carried out in isolated sites, it can be observed that a constant frequency can be maintained without introducing a control loop. Nevertheless, it is noted that the load variation is relatively limited.

\section{APPENDIX}

Both the test bench and the induction machine are characterized by: $380 \mathrm{~V} / 660 \mathrm{~V}, 7.3 \mathrm{~A} / 4.2 \mathrm{~A}, \cos \varphi=0.8$, $p=2,50 \mathrm{~Hz}, 1420 \mathrm{rpm}, 3 \mathrm{~kW}, \mathrm{n}^{\mathrm{s}} / \mathrm{n}^{\mathrm{r}}=\sqrt{2}, r^{r}=3 \Omega$, $L^{r}=267 m H, M^{s r}=377 m H, r^{a}=10 \Omega, M^{s a}=100 m H$, $l^{a}=5 \mathrm{mH}, L^{a}=18.7 \mathrm{mH}, \lambda^{a}=0.26, M^{r a}=\sqrt{L^{a} L^{r}}=70.6 \mathrm{mH}$, $L^{s}=534 m H, r^{s}=8.66 \Omega, r^{\prime r}=6 \Omega, l^{s}=24.24 m H ，$ $l^{\prime r}=36.36 \mathrm{mH}, \lambda^{s}=0.0454, \lambda^{r}=0.068, I_{D C_{\text {rat }}}=23 \mathrm{~A}$, $R_{D C}=0.63 \Omega, T_{f}=1.3 \mathrm{Nm}, \Gamma_{f D C}=0.9 \mathrm{Nm} \quad K_{D C}=1.26$, $U_{0}=280 \mathrm{~V} \quad U_{D C_{\text {rat }}}=220 \mathrm{~V}, L_{R}=215 \mathrm{mH} \quad$, and $C_{M}=113 \mu F$.

The rated values are: $380 \mathrm{~V} / 660 \mathrm{~V}, 7.3 \mathrm{~A} / 4.2 \mathrm{~A}, 50 \mathrm{~Hz}$, and $1420 \mathrm{rpm}$. However, the reference values are: $\quad V_{r e f}^{s}=223 \mathrm{~V} \quad, \quad s_{r e f}=5.4 \% . \quad, \quad I_{r e f}^{s}=2.42 \mathrm{~A}$, $\omega_{r e f}=\omega_{r a t}=314.2 r d s^{-1}$.

\section{REFERENCES}

[1] S. Heir, Grid Integration of Wind Energy Conversion Systems, John Wiley \& Sons, 1998.

[2] M. G. Simões and F. A. Farret, Renewable Energy Systems: Design and Analysis with Induction Generators, CRC PRESS, USA, 2004.

[3] P. Gipe, Evaluating the technology-what works and what doesn't, Chelsea Green Publishing Company, Wind Power for Home \& Business, 1993.

[4] G. K. Kasal and B. Singh, "Voltage and frequency controllers for an asynchronous generator-based isolated wind energy conversion system," IEEE Trans. Energy Convers., Vol. 26, No. 02, pp. 402-416, Jun. 2011.

[5] S. Boora, "Analysis of self-excited induction generator under balanced or unbalanced conditions," Internatinal Journal on Electrical and Power Engineering, Vol. 1, No. 3, pp. 59-63, Dec. 2010

[6] D. Seyoum, C. Grantham, and M. F. Rahman, "The dynamic characteristics of an isolated self-excited induction generator driven by a wind turbine," IEEE Trans. Ind. Appl., Vol. 39, No.4, pp. 936-944, Jul./Aug. 2003

[7] O. Chtchetinine, "Voltage stabilization system for induction generator in standalone mode," IEEE Trans. Energy Convers., Vol. 14, No. 4, pp. 298-303, Sep. 1999.

[8] M. H. Haque, "A novel method of evaluating performance characteristics of a self-excited induction generator," IEEE
Trans. Energy Convers., Vol. 24, No. 2, pp. 358-365, Jun. 2009.

[9] R. C. Bansal, "Three-phase self-excited induction generators: An Overview," IEEE Trans. Energy Convers. Vol. 20, No. 2, pp. 292-299, Jun. 2005.

[10] S. Kumar and R. Narayan, "Effect of capacitive VAR on performance of three-phase self excited induction generator," International Journal of Emerging Technology and Advanced Engineering, Vol. 12, No. 2, pp. 253-258, Dec. 2012.

[11] A. L. Alolah and M. A. Alkanthal, "Optimization based steady state analysis of three phase SEIG," IEEE Trans. Energy Convers., Vol. 15, No. 01, pp. 61-65, Mar. 2000.

[12] M. Radić, Z. Stajić, and N. Floranović, "Performance characteristics of a three-phase self-excited induction generator driven by regulated constant speed turbine," Automatic Control and Robotics, Vol. 11, No. 1, pp. 57-67, May 2012.

[13] B. V. Perumal and J. K. Chatterjee, "Voltage and frequency control of a stand-alone brushless wind electric generation using generalized impedance controller," IEEE Trans. Energy Convers., Vol. 23, No. 2, pp. 632-641, Jun. 2008.

[14] R. Bonert and S. Rajakaruna, "Self-excited Induction generators with excellent voltage and frequency control," in Proc. Inst. Electr. Eng. Trans. Distrib., Vol. 145, No. 1, pp. 33-39, 1998.

[15] B. Singh, S. S. Murthy, and S. Gupta, "Analysis and design of STATCOM based voltage regulator for self-excited Induction generators," IEEE Trans. Energy Convers., Vol. 19, No. 4, pp. 783-790, Dec. 2004.

[16] R. M. Hillowala and A. M. Sharaf, " A utility interactive wind energy conversion scheme with an asynchronous dc link using a supplementary control loop," IEEE Trans. Energy Convers., Vol. 9, No. 3, pp. 558-563, Sep. 1994.

[17] L. A. C. Lopes and R.G. de Almeida, "A wind driven self-excited induction generator with voltage and frequency regulated by a reduced rating voltage source inverter," IEEE Trans. Energy Convers., Vol. 21, No. 2, pp. 297-304, Jun. 2006.

[18] G. Dastagir and L. A. C. Lopes, "Voltage and frequency regulation of a stand-alone self-excited induction generator," IEEE Electrical Power Conference, pp. 502-506, 2007.

[19] S. C. Kuo and L. Wang, "Analysis of voltage control for a self-excited induction generator using a current controlled voltage source inverter (CCVSI)," in Proc. inst. Electr. Eng. Trans. Distrib., Vol. 148, No. 5, pp. 431-438, 2001.

[20] B. Singh, S. S. Murthy, and S. Gupta, "Analysis and implementation of an electronic load controller for a self-excited Induction generator," in Proc. IEE Gener. Transm. Distrib.,Vol. 151, No. 1, pp. 51-60, 2004.

[21] B. Singh, S. S. Murthy, and S. Gupta, "Analysis and design of an electronic load controller for self-excited Induction generators," IEEE Trans. Energy Convers., Vol. 21, No. 1, pp. 285-293, Mar. 2006.

[22] Y. K. Chauhan, S. K. Jain, and B. Singh, "A prospective on voltage regulation of self-excited induction generators for industry applications," IEEE Trans. Ind. Appl., Vol. 46, No. 2, pp. 720-730, Mar./Apr. 2010.

[23] J. M. Ramirez, and M. E. Torres, "An electronic load controller for the self-excited induction generator," IEEE Trans. Energy Convers., Vol. 22, No. 2, pp.546-548, Jun. 2007.

[24] B. V. Perumal and J. K. Chatterjee, "Voltage and frequency control of a stand alone brushless wind electric generation 
using generalized impedance controller," IEEE Trans. Energy Convers., Vol. 23, No. 2, pp. 632-641, Jun. 2008.

[25] J. K. Chatterjee, B. V. Perumal, and N. R. Gopu, "Analysis of operation of self-excited induction generator with generalized impedance controller," IEEE Trans. Energy Convers., Vol. 22, No. 2, pp. 307-315, Jun. 2007.

[26] E. G. Marra and J. A. Pomilio, "Self-excited induction generator controlled by a VS-PWM bidirectional converter for rural applications," IEEE Trans. Ind. Appl., Vol. 35, No. 4, pp. 877- 883, Jul./Aug. 1999.

[27] E. Suarez and G. Bortolotto, "Voltage-frequency control of a self excited induction generator," IEEE Trans. Energy Convers., Vol. 14, No. 3, pp. 394-401, Sep. 1999.

[28] L. Louze, A. L. Nemmour, A. Khezzar, M. E. Hacil, and M. Boucherma, "Cascade sliding mode controller for self-excited induction generator," Renewable Energy Review, Vol. 12, No. 4, pp. 617-626, Dec. 2009.

[29] J. F. Brudny, R. Pusca, and H. Roisse, "Wind turbines using self-excited three-phase induction generators: an innovative solution for voltage-frequency control," Eur. Phys. J. Appl. Phys., Vol. 43, No. 2, pp. 173-187, Jul. 2008.

[30] C.-K. Kim, Y.-D. Choy, and S.-J. Lim, "Transient simulation of a self-excited induction generator during grid faults," Journal of Power Electronics, Vol. 7, No. 2, pp. 89-96, Apr. 2007.

[31] J. Fraile-Ardanuy, J. Fraile-Mora, and P. A. Garcia-Gutierrez, "Voltage control of isolated self- excited induction generator through series compensation," Przeglad Elektrotechniczny (Electrical Review), Vol. 2012, No. 1a, pp. 132-136, 2012.

[32] J. F. Brudny, H. Roisse, and G. Peset, "Practical approaches for the study of wind machine self-excited induction generators," Int. Conf. on Wind energy and remote regions, pp. 13-24, 2005.

[33] E. Touti, R. Pusca, and A. Chaari, "Dimmer control for voltage transient performance improvement in isolated wind turbine," Wulfenia Journal, Vol. 20, No. 4, pp. 108-117, Apr. 2013.

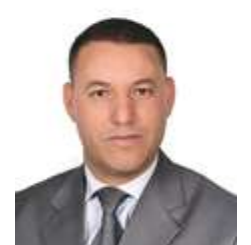

Ezzeddine Touti was born in Kasserine, Tunisia, in December 1972. He received his B.S. degree in Electrical Engineering from the Ecole Supérieure des Sciences et Techniques de Tunis (ESSTT), Tunis, Tunisia, and his M.S. degree in Electrical Engineering from the Ecole Nationale d'Ingénieurs de Tunis (ENIT), Tunis, Tunisia, in 2005. From 2007 to 2014, he was an Aggregate Teacher at the Institut Supérieur des Etudes Technologiques (ISET) de Radés, Tunisia. His current research interests include electrical machines, power electronics and renewable energy.

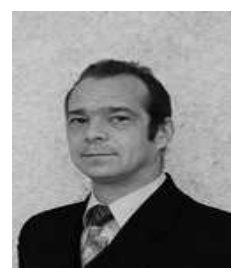

Remus Pusca was born in Medias, Romania, in 1972. He received a degree in Electrical Engineering from Technical University of Cluj-Napoca, Romania, in 1995. He received his Ph.D. degree in Electrical Engineering, from the University of Franche-Comté, France, in 2002. In 2003, he joined the Laboratory of Electrical Systems and Environment (LSEE), Artois University, Béthune, France, as an Associate Professor and Researcher. His current research interest include the control of electrical systems and the diagnosis of electrical machines.

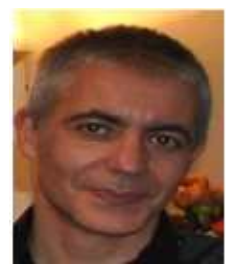

Jean-Paul Manata was born in Mira, Portugal, in 1969. He received his Ph.D. degree in Control Systems from the University of Nancy, Lorraine, France, in 1996. He is currently an Associate Professor at University of Artois, Arras, France. His current research interests include induction machines, wind turbines, life cycle assessment and programmable logic controllers.

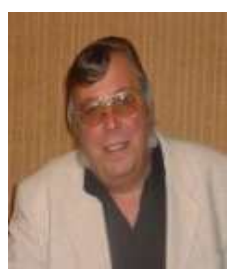

Jean François Brudny received his Ph.D. and D.Sc. degrees from Lille University, Lille, France, in 1984 and 1991, respectively. In 1992 he joined the University of Artois, Arras, France, as a Full Professor. He is the head of the Electromechanical Systems and Environment Research Laboratory (EA 4025). His current research interests include the noise and vibrations of electromechanical systems and new designs for increasing the efficiency of $\mathrm{AC}$ rotating electrical machines.

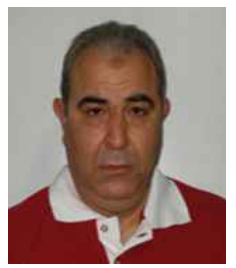

Abdelkader Châari was born in Sfax, Tunisia, on November 25, 1957. He received his DEA degree in Automatics from the Ecole Normale Superieure de l'Enseignement Technique de Tunis (ENSET), Tunis, Tunisia, in 1982, and his $\mathrm{Ph} . D$. degree in Electrical Engineering with a focus on Identification and Control Self-adjustment Application for DC Motors from the Habilitation University, Tunis, Tunisia, in 2008. Since 1982, he has been with the School of Sciences and Techniques at Tunis, (Ecole Supérieure des Sciences et Techniques de Tunis (E.S.S.T.T.)) Tunis, Tunisia, as an Assistant Professor. He is presently responsible of a research unit on control, monitoring, and system safety (C3S: Commande, Surveillance et Sûreté de fonctionnement des Systèmes) at E.S.S.T.T. His current research interests include the identification and control of nonlinear systems, robust estimation and robust filtering. 